\title{
Perceived Benefits and Effectiveness of Tier 2 of the 3 Tier Pension Scheme Among Public Sector Staff in Central Region
}

\author{
Paul Andoh \\ Senior Assistant Auditor, Cape Coast Technical University
}

\begin{abstract}
The paper focused on exploring the management of tier 2 of the 3 tier pension scheme in Ghana. The papers focuses on the public sector staff assessment of the extent to which the tier 2 could smoothen their consumption on retirement and the effectiveness of the management of the tier 2 . The paper was motivated by the fact that while the tier 1 is a common knowledge to most workers, the tier 2 data are not too obvious. Therefore, it is critical to assess how this could affect workers' perception about the management of the tier 2 . The paper employs data from metropolitan, municipal and district assemblies (MMDAs) in Central Region of Ghana. Pure qualitative research approach was employed within the framework of exploratory design. The paper revealed that the participants perceive that the tier 2 could not contribute significantly to smoothen their future consumption on retirement. It was also found that participants doubt the effectiveness of the tier 2 of the pension scheme due to inadequate information and weaknesses in transparency. The paper concluded that the effectiveness of the Tier 2 pension management is not satisfactory. The paper further revealed that many of the people in the public sector cannot ascertain the true benefit of the Tier 2 scheme on their future pension. It is therefore recommended for government to organise workshops or seminars to educate their employees in the public sector on their pension schemes, identify the prospects and challenges associated with the scheme early enough to assist workers to make informed decisions about their retirement.
\end{abstract}

Keywords: Three Tier Pension Scheme; Mandatory Tier 2, Smoothen Consumption and Pension Benefits

DOI: $10.7176 / \mathrm{EJBM} / 12-26-06$

Publication date:September $30^{\text {th }} 2020$

\subsection{Introduction}

The increasing proportion of older persons in population across all rafters of the world has given rise to an increasing need to ensure financial security for this growing number of older persons. It is reported that Japan in the Asian Regions and as well as many European countries like Germany and Italy has close to $30 \%$ of the total population to be more than 65 years (Poterba, 2019; Slaug, Granbom \& Iwarsson, 2020). The concept of aging population and the principle of unforeseen contingencies has necessitated the need for interventions to protect and care for people in their old age. Previously, this protection against unforeseen contingencies of old age was performed by families and charity organisations. However, as society evolved into modern technology, family and charity organisational care for old has become unsustainable, thus giving way for new institutions with legal obligations of protecting individual citizens (Badu, Kissi, Boateng \& Antwi-Afari, 2018; Kamath, \& Patil, 2017).

Almost all countries, including those in Africa have set up vibrant institutions regulated by laws to formulate policies aimed at protecting people in their old age. To achieve this, these institutions make provisions for workers to save some percentage of their income (while working) in the form of insurance which protect them once they are retired. The percentage of money saved as insurance in order to be protected at old age is what researchers define as social security or pension schemes (Badu et al 2018; Bogataj, \& Bogataj, 2017; Platanakis \& Sutcliffe, 2017). Throwing more light on the concept of pension schemes, Platanakis and Sutcliffe, (2017) explained that pension schemes are long term investment vehicle whose principal objective is to provide decent and reliable income upon retirement. The implication is that a pension scheme should be seen as a social and economic necessity that society should embrace in the quest to alleviate poverty and provide economic security that will enable individuals to cope with life's major risks.

Currently in Ghana, the Social Security and Insurance Trust (SSNIT) is the institution mandated by law to managing the resources of people for purposes of social security against future risk especially in times of old age. Before, this institution, the quest to provide social protection for people in times of old age have gone through various reforms. Notable of these included, the CAP 30 (Quartey, Kunawotor, \& Danquah, 2016; Aikins, \& Apt, 2016), the compulsory savings Act (Act 70) in 1960 Social Security Act of 1965 (Act 279), the Provident fund scheme or provident funds from 1970 to 1990 (Ofori-Abebrese, Pickson \& Abubakari, 2017). The main difference between the SSNIT scheme and the previous one was the shift from a lump-sum payment to a monthly payment of retirement benefits. The contributions made by both employers and their employees under the old scheme were however maintained. Under the new scheme, participants must have demonstrated at least 240 months (20 years) of contribution to the scheme to qualify for retirement benefits. The scheme was designed for three main contingencies namely; old age and retirement, invalidity or disability and lastly dependents or survival's benefits (Ofori-Abebrese, et al. 2017). 
This SSNIT pension scheme is operating under the National Pensions Regulatory Authority 2012. The SSNIT scheme plays an important role under this new regulation. Like previous reforms which comes with dimensions and the new pension reforms consist of three tiers (Okine, 2012). The first tier is a mandatory occupational scheme which is run by SSNIT. Unlike the first tier, the second tier is also a mandatory occupational scheme which will be managed by private fund managers. However, the third tier is a voluntary scheme which would also be managed by private fund managers and give individuals the opportunity to freely open provident funds and personal pension schemes (Younger, Osei-Assibey, \& Oppong, 2017).

The provision outlined in the three-tier pension scheme in relation to previous pension schemes raises doubt on its benefits to the ordinary Ghanaian. With the first tier, contributors see the deduction of 5.5\% of the monthly salary and hence believe that their corporate institutions make such payment to SSNIT monthly. Just like the first tier, the second tier also deals with mandatory contribution. However, such mandatory contribution is run by independent fund management instead of the first fund which is run by SSNIT. Much as the effectiveness of this entire three-tier pension scheme has been investigated by some researchers (Darko, 2016; Kpessa, 2011; OfeiKwapong, 2013) though inconclusive, actual benefits of each of the block (Tier 1, Tier 2 and Tier 3 ) to beneficiaries is yet to receive any research attention.

Within the public sector, government is expected to give the Tier 2 funds to private fund management entities to manage it in behalf of the employees in the sector. However, it is believed that many staff within the various public sectors are oblivious about the three-tier pension schemes and its impact on their retirement (Darko, 2016). Many of these staff are only aware of the first tier which is contributed to SSNIT monthly. Meanwhile, few people from the public sector like the members of the University Teachers Association (UTAG) are very much aware of the tier two scheme and committed their funds to superannuation. It is therefore important to assess or examine the perception of other staff members within the public sector. It is against this background that the current study focusses its attention on public servants from metropolitan, municipal and district assemblies (MMDAs) in Central Region of Ghana.

\section{Statement of the problem}

The introduction of the recent three-tier pension scheme is quite new and as such there is limited literature with regards to its effectiveness. As indicated in the background, most workers do not understand its current structure, the role of the new players and exactly how high pension benefits under the new scheme can be obtained (Boamah, 2015). Furthermore, the lack of comprehensive understanding of the three tier pensions scheme makes it difficult for staff or workers follow the rudiments of each block of the new model. Additionally, there is a of lack coordination among the managers of the three components of the current three-tier pension scheme. Therefore, the perception of how each of them and for that matter tier 2 contributes to staff pension cannot be readily ascertained (Afrane, Owusu-Manu,Donkor-Hyiaman, \& Bondinuba, 2016; Ofei-Kwapong, 2013).

Additionally, the tier 2 pension scheme is designed with the aim of providing beneficiaries the optimum control on returns based on the choice of fund management. However, it is believed that most staff of the public sector are oblivious of the fund managers their Tier 2 pension contribution. This has left many contributors in doubt as to whether the government is really paying the Tier 2 or otherwise. If indeed this Tier 2 is being paid, the important question is whether or not contributors are fully aware its impact on their pension benefits. In view or the forgoing problem the study seeks to assess the perception of public staff in MMDAs within Central region about the extent of tier 2 contribution to smoothen pensioners' consumption and examine the effectiveness in the management of Tier 2 pension scheme in public sector

\subsection{Literature Review}

This section of the study provides both theoretical and empirical justification for the study. The theoretical analysis provides basis and assumption which guide the study. The empirical review provides information on contemporary development made in literature as far as management of pension schemes are concerned. Furthermore, key concepts of the study have also been outlined in this section.

\subsubsection{Theoretical Review}

The study employs two theories for the purpose of supporting the various argument raised in the study. Each of these theories proposes different assumptions which provide theoretical framework for the study. The two theories employed in the study are the permanent income hypothesis and the rational choice theory

\subsubsection{Permanent Income Hypothesis (PIH)}

The permanent income hypothesis has its origin from the work of Friedman (1957). Milton Friedman's permanent income hypothesis was basically an intuition that individuals would wish to smooth consumption and not let it fluctuate with short-run fluctuations in income. The assumption of the theory is that people base their consumption on a longer-term view of an income measured, perhaps a notion of lifetime wealth or a notion of wealth over a reasonable length of time.

The Permanent Income Hypothesis model indicates that incomes of various households change and thus 
decreases as time passes by since incomes earned from their economic activities are not permanent. The model comprises the permanent income and transitory income. The theory further explains permanent income as the one which an individual tends to gain and save throughout their life time which they also presume that this income can be used in the future as well. However, transitory income was explained as the income households do not expect but gain and diminishes over a period of time. The theory proposes that the income saving attitude of individuals should be consistent throughout their working age (Kpessa, 2011) to make life at retirement less burdensome. The basic reason is that during retirement, consumption should not depreciate since household's consumption does not fully depend on social security but rather the permanent income.

The assumptions in the PIH indicates that aside the implementation of compulsory retirement security scheme, individuals also have the tendency to save provided their prevailing income permit. That is to say that, individual workers have the desire to save for the future in order for their household consumption not to depreciate upon retirement but rather put them on a level platform or provide permanent income. Thus, the introduction of the Tier 2 pension scheme which afford workers to appoint their fund management for their retirement benefits should be as transparent as the Tier 1.

Additionally, the implication of this theory as far as the current study is concerned is that many stakeholders are of the view that management of pensions schemes which stems from the deduction of contributor's income should be left for individual workers or better yet their trade union. However, within the public sector, how the government is treating the Tier 2 is oblivious to the workers and hence cast doubt on its potential impact on their pensions (Alidu, Dankyi, \& Tsiboe-Darko, 2016).

A critical review of the PIH reveals that when workers are aware of the benefits accruing to them in the second tier, they could reassess their future consumption vis-à-vis the expected benefits from the second tier and make decision on further savings. Thus, when workers are able to realize that their expected benefits from the second tier in addition to the first tier cannot meet their future consumption, they could undertake further savings to smoothen their future in order not to be worse-off on retirement. The implication is that weakness in the transparency in the second tier management of the public workers could make them reach state of indecision and may also trigger consumption cut which could make life difficult on retirement. On the other hand, following PIH when the public staff are adequately informed about the management and performance of their tier two, they could be in better position to smooth their consumption. The paper therefore follows the lessons from the PIH to raise theoretical question as follows:

RQ1: What is the perception about the extent to which the tier 2 smoothen the consumption of public workers on retirement?

RQ2: What is the level of effectiveness in the management of Tier 2 pension scheme in public sector?

\subsubsection{Rational Choice Theory}

The Rational Choice Theory (RCT) was popularised and applied more widely by Becker (1976). Rational choice theory is the idea that people make choices in ways that are advantageous to them while at the same time reducing cost (Simon, 1978). Rationality as used in the theory simply means acting to maximise personal advantage by balancing costs against benefits (Friedman, 1994). Scott (2000) argues that individuals are motivated by the goals that work to their advantage. However, because individuals are not able to achieve all their goals, they are usually faced with the problem of making choices. Elster (1989) therefore stated that people choose the option they think will yield the best outcome when faced with alternative courses of action.

One of the basic assumptions of the theory is that individual decision makers have accurate information and knowledge of the situation for which such decision is to be made. Individuals therefore act based on the information, given the constraints and the conditions under which they are acting (Scott, 2000). To fully benefit from whatever decision made, the theory maintains that the outcomes of alternative courses of action must be anticipated by individuals for them to be able to calculate and choose what will be best for them. The implication then is that alternatives likely to give the best satisfaction are then rational (Boudon, 2009; Hindmoor \& Taylor 2015).

Following these assumptions, for the public workers to make an informed decision and rational choice about their pension, they should be fully aware of the operational mechanisms and management of their schemes including the second tier. Therefore, to assess the effectiveness of the tier 2, the paper first assesses the informative based awareness by theses staff. This means that using the rational choice theory, the effectiveness of the new Tier 2 pension scheme management in the public sector cannot be fully ascertain if staff have little or no idea of how their monies are managed. However, it could also be argued that if contributor's satisfaction is met with current provisions in the new scheme, then from the theory contributors have made an optimal choice.

The argument that emerges from making informed decision as far as the rational choice theory is concerned is based on thorough knowledge. Hence, if the public sector staff has all the information concerning the management of the Tier 2, it broadens their knowledge on it and hence lessens the agitation against it. More knowledge on the scheme would also mean greater cooperation from the contributors (Yeboah, 2015). Once there is more cooperation, it increases the efficacy of the system hence its effectiveness.

Classically, rational action has been taken generally to imply conscious individual involved in a deliberate 
calculative strategy (Scott, 2000). As argued by Homans (1961), human behaviour is not free but determined. Similarly, Ofei-Kwapong (2013) stressed that people make optimal spending and saving decisions for both their present and future needs based on all resources available to them at a given time. These resources include knowledge of their pension scheme and how they perceive it affects their retirement in the future. This follows the assumption of self-regarding interest by the rational choice theory. This assumption states that, an individual's actions are fully concerned with their own welfare (Afrane, et al, 2016). Similarly, people assess the degree to which personal circumstances such as how retiring can impact on their lives, and then adjust their consumption and saving patterns accordingly (Ahmad \& Emeka, 2014). This reflects their desire to maintain a consistent standard of living throughout life (Donkor, 2016; Hindmoor \& Taylor, 2015).

\subsubsection{Empirical Review}

In a study, Ofei-Kwapong, (2013) investigated the role and effectiveness of Ghana's new three tier pension scheme in providing and ensuring income security for Ghanaians in their old age. It was also proven that the scheme is more accountable and transparent than the SSNIT scheme that pre dated it. The findings revealed that, although many Ghanaian workers especially those belonging to the financial sector are aware of the new scheme, they do not understand its current structure, the role of the new players and exactly how high pension benefits under the new scheme can be obtained. The implication of the study then is that, it is the duty of the National Pensions Regulatory Body to set up efforts in educating the public on the new pension scheme with particular focus on its new structure, the role of the new stakeholders and its benefits

Focusing on efficiency, Boamah (2015) conducted a study to examine the efficiency of the new SSNIT threetier pension scheme in Ghanaian. The result from the research indicated that the new three tier pension scheme is indeed an effective scheme because it delivers on its promise of higher pension benefits for its current contributors. It was also proven that the scheme is more accountable and transparent than the Cap 30 . The result also indicated that considering the cost and contribution of members, the new scheme was beneficial to them. The result further indicated that workers were not pleased with government managing the second (2nd) tier. The workers also stated that they are not sure if the scheme could be sustained.

Discussing the merits of the new pension scheme, Mumba, (2016) analysed the newly introduced three-tier pension scheme in Ghana, showing that major transformation in the country's overall pension system was the insertion of two private - mandatory and voluntary - pillars to the existing social insurance scheme. The analysis showed that although private pensions were projected as instruments for giving individual citizens choice and freedom over their retirement decisions, the design of the three-tier scheme in Ghana has several risks and institutional weaknesses that can compromise the income security of the aged. Thus, it argued for the need to reform the new scheme by establishing a statutory pension benefit insurance; scaling back the number of pension service providers; capping amount of each contributors funds that service providers can spend on administrative issues; and activating constitutional provisions on social assistance to augment the threetier model. The implication of the study is that the new scheme still has loopholes that need rectification.

In a similar study, Donkor (2016) took a holistic assessment of pension scheme in the country and associated risk. The findings put managers of the pension scheme in a position that seems to enhance the advantages of the scheme to beneficiaries. Although the study was organised from a simulation point of view. No matter how real a simulation is, it may not substantially reflect real life experience. Simulation often follows assumptions which may not reflect the practice. Thus, there is the need to conduct a real-life analysis where the findings could easily be related and lesson drawn for effective implementation. That is why the current study seeks to unveil the various means through which the new three tier provision provides alternative solution to infractions in the old ones

In another study, Afrane, Owusu-Manu, Donkor-Hyiaman,and Bondinuba, (2016) examined alternative sources of retirement income apart from the Social Security and National Insurance Trust (SSNIT) pension benefits and the significance of these retirement income sources in the consumption decisions of pensioners in Ghana. The findings show that apart from SSNIT pension benefits, other sources of retirement income including rental income, income from post-retirement jobs and remittances from family and friends are significant sources of income for pensioners in Ghana. Personnel savings and investment was the least important source of retirement income

A more similar study to the current study was conducted by Darko, (2016). The purpose of the study was to investigate the effectiveness of the current tier-three pension scheme in providing adequate social security for Ghanaians. Based on the findings, the study recommended that there should be a continuous and effective collaboration of all stakeholders in connection with the new pension scheme in order to ensure effective working of the scheme. Additionally, public education and sensitisation should be provided to ensure people understand all components of the scheme in order to increase the number of enrolment and sustainability of the scheme. Further, the implementation should provide an opportunity to use future lump sum pension benefits to secure mortgages. However, stakeholder collaboration in ensuring the effectiveness of the scheme has not received the needed attention that it deserves. It thus becomes imperative for the views of public sectors workers who are also key stakeholders on the pension scheme to be interrogated.

In 2019, Ashong, (2019) examined the extent to which the current reforms in SSNIT have affected its financial 
viability of SSNIT as an institution and also assesses which of the two pension laws of Ghana makes beneficiaries better off. The study adopts a mixed method which consist of both quantitative and qualitative methods. The descriptive statistics showed majority of the respondents indicated that the number of pensions paid to them is not enough to enhance their living standards hence, not sustainable. The transfer of $5 \%$ contribution to second tier fund managers does not have any effect on SSNIT in the short term. Also, SSNIT beneficiaries are better off in receiving their benefits. It also concluded that the scheme has remained solvent over the period but it is close to reaching equilibrium where total income will be equal to total expenses. The adoption of descriptive statistics by Ashong, (2019) revealed statistical viability of the scheme. The current study uses exploratory analysis to investigate other aspects of the scheme like perception of stakeholders which was not captured statistically. Moreover, the findings from Ashong, (2019) on the benefits of SSNIT contradicts earlier findings by OfeiKwapong, (2013). While Ofei-Kwapong reported that workers do not fully understand the tenets of the new scheme and any benefit, Ashong, (2019) reports revealed that a number of workers has trust in the new scheme.

\subsubsection{Conceptual Review}

This section deals with some of the key variables of the study in literature. Some of these key variables include, history of pension schemes in Ghana, The three-tier pension scheme and the perception of stakeholders on the new pension scheme.

\subsubsection{History of Pension Schemes in Ghana}

Social security in Ghana embraces old-age persons, survivor benefits, and Disability pensions. In Ghana, the social security system was modeled after the British system, when the country was colonised for almost 108 years (Mumba, 2016). The British enacted the colonial Development and welfare Act in the 1940s to support the development of social security. The primary beneficiaries of the program during the colonial era were Europeans and some Africans who worked in the public services (Afrane et al 2016).

The social security system was designed to cater for the needs of workers in the formal sector, more especially, those residing in the urban area. However, in Ghana, about $85 \%$ of the population falls within the informal sector of the economy and this presented opportunity to government to design a scheme to cater for the needs of this broader sector of the population (Ashong, 2019). The decision to broaden the pension horizon brought about the initiation of the CAP 30. In fact, Kpessa (2010) argued that the reason behind the introduction of the CAP 30 was to encourage loyalty and efficiency within the colonial civil service. The retirement benefit was not one that was carved from deferred incomes by the retiree but rather it was seen and considered as a reward for people who served the Queen and the colony diligently until their old age. Thus, public servants had no claim to such programs unless they were umpired by colonial administrators as meeting eligibility requirement of loyalty (Afrane et al, 2016).

As time progressed, stakeholders identified major weaknesses in the CAP 30. As a result of the financial burdens inherent in the scheme, policy makers after independence opted for the establishment of a new and different pension scheme to be recognized as Provident funds in 1965 for all groups of workers that were not covered by the CAP 30 scheme at that time (Kpessa, 2010). Government by then introduced a more developed national scheme to cover all workers for both the private and public sector workers. The term provident fund refers to a pension plan under which retiring workers received lump sum benefits in the form of financial assets build up over a period of time through membership contributions and investment returns (Donkor, 2016). This was a type of defined contribution since the employer (government) contributes funds to the scheme,' but the employee bears all the risk of the fund's investment performance. Under this arrangement an individual's pension annuity size, at any given life expectancy and rate of interest, is determined only by the size of his or her lifetime pension contribution. The Provident Fund provided a lump sum payment for the old-age, invalidity and survivor's benefits.

Kpessa (2010) posits that in 1991 when the scheme was introduced, the total numbers of active members were about 647,712. Social Security and National Insurance Trust in 2006 also reported that by the close of that same year the active members increased to $1,211,620$ members, who represents $87.06 \%$ increase within the fifteen years of establishment and at the close of that year the scheme recorded a total contribution of 2,868 billion old cedis (Kpessa, 2010). With this type of insurance, the employee contributes 5\% whiles the employer contributes $12.5 \%$ making a total contribution of $17.5 \%$. The most interesting aspect of the social insurance plans has to do with the fact that it ensures inter-generational transfers and intended to ensure cohesion and collectivisation of risks (Kpessa, 2010). Funds or contributions from the scheme are invested in numerous sections of the economy like financial, manufacturing, services, residential (real estate), and commercial properties. Generally, the investment portfolio of the scheme is divided into fixed and non-fixed income investments. The fixed income investments include registered stocks, home finance company index-linked bonds, fixed deposits, call monies, student loans, corporate loans, treasury bills and government bonds and most of these investments are mostly short term. "Non-fixed income investments are economically targeted investment such as real estate, commercial and residential, development and equities.

The new Three-Tier Pension Scheme in Ghana will further throw more light on the Scheme making up of three separate sources one can save towards retirement (Agbobli, 2010). This pension reform has its firm grounds 
from National Pensions Act, 2008 (Act 766). The new scheme consists of three strong investment pillars upon which it revolves, with introduction geared towards bringing relief to the pensioner or their beneficiaries. It is arranged as follows; First-Tier is a mandatory basic national social security scheme which will integrate an improved system of SSNIT benefits mandatory for all employees in both the private and public sector (no lump sum payment, only monthly income replacement and related benefits such as survivor benefit, invalidity pension.) are currently paid by SSNIT (National Pension Act 2008). Second-Tier is an occupational pension scheme, mandatory for all employees but privately managed by registered Pension Fund Managers and Custodians who are regulated by approved trustees licensed by the NPRA, and designed primarily to give contributors higher lump sum benefits than presently available under the SSNIT or Cap 30 pension schemes (National Pensions Act, 2008). Third-Tier voluntary provident fund and personal scheme/ is also supported by tax incentives. It is pertinent to note that this 3rd-tier voluntary personal pensions being managed by Pension Fund Managers seeks to address the needs of workers in the informal sector and also designed to provide an additional fund for formal sector workers who want to make voluntary contributions to enhance their pension benefits (National Pensions Act, 2008).

With the introduction of the new three-tier pension scheme, the employer now contributes $13 \%$ and the employee contributes $5.5 \%$ making a total of $18.5 \%$. This shows an increase of $1 \%$ contribution on the old social security scheme. This additional increment was spread among the employee and the employer. Though the $1 \%$ increase on paper looks quantitatively small, but the benefits are much higher and more rewarding. The benefits of this retirement scheme are monthly pension income, lump sum payment, invalidity benefits, survivor benefits and a favorable tax exemption from investments (National Pension Regulatory Authority 2010).

\subsubsection{The Three Tier Pension Scheme}

One of the underlying features of the new pension scheme is the fact that, it was drafted with the socio- cultural environment of Ghanaians at heart. For instance, the commission set up to create the new scheme was cognisant of the fact that in Ghana, the needs of individuals rather increase upon retirement due to demands placed on the aged such as family engagements and other social responsibilities. In addition to being an entirely new scheme, the new 3-tier scheme is believed to be in many ways better than the preexisting CAP 30 and SSNIT pension schemes.

Darko (2016) outlined some of these distinguishing features which double as benefits of the new scheme. The author asserted that there is an improvement in the entry/maximum age at which a person may join the social security scheme. The new entry has been reduced from 20 years to 15 years while the new maximum age is 45 years. Moreover, there is an improvement in the second-tier lump sum benefits or returns that are higher than the benefits under the CAP 30 scheme and far higher than that of the SSNIT scheme. This is probably due to the fact that this tier is privately managed and as such will be invested in high yielding investments. Furthermore, there is an opportunity to use future lump sum pension benefits to secure mortgages. This gives a worker the opportunity to own his or her own house before retirement by using their pension benefits as collateral.

Another important thing under the new pension scheme is the rate of contribution. The rates of contribution under this new scheme have been reviewed under the new National Pensions Act, 2008, Act 766. There is an additional contribution rate of $1 \%$ to be shared equally by the employer and employee. This additional contribution is almost cost neutral, but the additional benefits are much higher and more rewarding though on paper it may seem small. The employer will now pay $13 \%$ instead of the initial $12.5 \%$ and the worker will now pay $5.5 \%$ instead of the $5 \%$ making a total contribution of $18.5 \%$ instead of the $17.5 \%$. These developments as seen in the new scheme are according to Donkor (2016) an improvement in the old ones.

Although on paper, the new three-tier pension scheme is seemingly the perfect solution to the inconsistencies, agitation, and protest existing in the SSNIT specifically, with its declining investment returns and improving access to informal sectors. It has encountered its share of scrutiny and difficulties prior to its implementation. Literature from Graphic Business revealed that management of the National Pensions Regulatory Authority (NPRA), the body responsible for licensing and regulating all pension related activities including its three main players, has been involved in the mismanagement of individuals' contributions. The NPRA, in 2010, set up a Temporary Pension Fund (TPF) to provisionally administer Tier 2 contributions pending the licensing of Trustees. As a result, employees have been paying $5 \%$ of their salaries to the TPF (Okine, 2012). Though the implementation of the new three-tier is still young, in 2015 the National Pension act (Act, 883) introduced some major amendments under the first-tier. These included the age limit exemption, payment of emigration benefits to non-Ghanaian, the computation of pension rights and other related matters.

\subsection{Methodology}

This section of the paper discusses the methodology employed in this paper. The paper follows pure qualitative approach. According to Creswell, (2009), qualitative approach is appropriate when a study seeks to give priority to target audiences, their culture or situation and involves direct interaction with respondents. This current paper seeks to interact with some key informants about the scheme. This approach is applied by design interview guide to support the data collection. 


\subsubsection{Target Population and Sampling}

The population of the study consisted of all the twenty-three (23) MMDAs in the region. These MMDAs have a total of 230 public servants. However, according to Hennink, Hutter and Bailey, (2020), qualitative survey through interviews do not require large sample size. Thus, the study uses simple random sampling to select 25 public servants from the total population.

\subsubsection{Research Instrument}

The study used primary data source. This primary data is sourced using interview with the participants. Interview is a two-way conversation method which permits an exchange of ideas and information (Harvey, 2015). According to Sidhu (2015), the use of interview involves collection of data through direct verbal interaction between the interviewee and interviewer. Interviews require the actual physical proximity of the two or more people involved. In this study, the semi-structured interview was used to gather data for the study. The semi-structured interview was the information collection technique used to interview.

\subsubsection{Data analysis}

The paper follows content and thematic analysis to analyse the data generated through the interviews. All the interviews are recorded with the participants' permission. The paper follows the content and thematic analysis procedures adopted by Queku (2017) in the data analysis. Queku (2017) followed a six stage procedures in applying content and thematic analysis:

The procedures adopted in this study to develop the models are as follows:

i. Data analysis procedure starts with thorough and repeated reading of all relevant text data. The purpose of this step is to obtain deeper and clearer understanding of the whole text data.

ii. Secondly, the text data are read again but at this stage the reading is done 'word by word' This intends to help develop relevant codes. The study therefore highlights key words in the text that capture or convey core thoughts.

iii. The next step is the note-making stage. The study continuous the process by reading to make notes from the text data. The notes capture issues of interest and provide labels to support the coding. This forms the first stage of the codes

iv. The study subsequently sorts the codes into categories based on similarities between codes. This is part of the data reduction process.

v. Finally, the study would further reduce the categories by organising into meaning themes based on the research questions. These themes are the bases for answering the research questions

vi. The paper reviews other evidences in the literature to support the themes.

\subsection{Results and Discussion}

Out of the total sampled size of 25 scheduled to have participated in the interview for data gathering, 21 actually participated representing $84 \%$. This response rate is above $70 \%$ which is referred to as very good according to Kothari (2007). This section presents the results in respect of the two research questions.

What is the perception about the extent to which the tier 2 smoothen the consumption of public workers on retirement?

The first research question was geared towards the perception about the extent to which the tier 2 smoothen the consumption of public workers on retirement.

One of the first question on the perception of stakeholder on the scheme was about awareness. The responses revealed that most of the participants are aware of the tier 2 pension scheme. However, such information was only on its existence and not the rudiments of the scheme. One of the participants indicated that

"I am full of aware of the tier 2. However. I do not have enough information on its operations and how I can benefit in future" (PT \# 1). Another respondent stated that

"I know the tier 2 is supposed to be run by private pension fund management. As at now I do not know how much I have contributed and how much I am likely to obtain at the end of my working service' (PT\#9)

When asked about the percentage of contribution towards the tier 2, almost all the participants could not provide the accurate response. Surprisingly, some of the finance officers even could not answer it correctly.

“....................................I don't remember the percentage of contribution I am told controller

makes deduction for such contribution.... "(PT \# 11).

It was revealed by another respondent that

".........................previously they were deducting 17.5\% for the SSNIT. Now it is rather 18.5\%. I think the $1 \%$ goes to the tier 2 ....... "(PT \# 3).

The response given by PT \# 3 shows that the participant had relevant knowledge about the tier 2, however, the knowledge was not sufficient-appropriate. Although the first two submissions were right, the contribution to tier 2 is not $1 \%$.

One of the primary focus of the tier 2 is to provide pensioners with lump sum which could be an important source of investible funds and may also serve as guarantee for mortgage loans. These could contribute to smoothen 
pensioners' consumption as the returns from this funds would support the monthly payment from the tier 1 . By extrapolation, one could then state that tier 2 is a very important aspect of the scheme to make the pensioners not worse off. However, given the PIH and RCT, accurate information and knowledge are required for workers to reevaluate their affairs to smoothen their consumption through this scheme. Unfortunately, the responses from the subsidiary questions suggest that the participants do not have appreciable knowledge about the scheme which according to reviewed theories could negatively affect their future consumption. The paper therefore presented the main question as: What is the perception about the extent to which the tier 2 smoothen the consumption of public workers on retirement?

The responses partly affirm the PIT and RCT. Some of the responses provided as follows:

".................Hmmmm! I have arranged with my family to cut down our expenditure so we can make enough savings when I go on retirement. In fact, if you fail to do this and rely on this scheme you would live to regret......You may turn to sell your property to meet your daily consumption..... "(PT\# 17)

“............I attended some seminar and learnt that I can use my tier 2 for mortgage loan. I wish I can use that to address my accommodation needs.........I don't want to use my retirement benefits to build. Unfortunately, I don't have much information on my tier 2 ..................Eventually I would have to sacrifice my consumption during my retirement to build. This is quite unfortunate........" (PT\#9)

I have arranged with my family to cut down our expenditure so we can make enough savings when I go on retirement. In fact, if you fail to do this and rely on this scheme you would live to regret......You may turn to sell your property to meet your daily consumption...............” (PT\# 17)

"My brother, how many pensioners in the public sector have been living comfortably after retirement?.............private sector workers are often better off because they have full knowledge about their pension funds and therefore could plan about their benefits thereof as well as the consumption...................." (PT\#5)

The general implication of these responses is that the participants do not consider the tier 2 as an important contributor to smoothen their future consumption. An evaluation of their responses seem to suggest that the public sector workers negative perception about the weakness of the tier 2 in smoothen their consumption is NOT about the structure weakness but rather about lack of sufficient appropriate knowledge about the tier 2 . Thus, their poor knowledge about the scheme has informed their negative perception. This is consistent with the permanent income hypothesis. According to PIH, when workers are aware of the benefits accruing to them in the second tier, they could reassess their future consumption vis-à-vis the expected benefits from the second tier and make decision on further savings. Thus, when workers are able to realize that their expected benefits from the second tier in addition to the first tier cannot meet their future consumption, they could undertake further savings to smoothen their future in order not to be worse-off on retirement (Alidu, et al, 2016). Thus, lack of appreciable knowledge caused the participants to perceive that the tier 2 cannot smoothen their consumption on retirement.

The findings further imply that the participants doubt the potency of the tier 2 to contribute significantly to protect the future benefits of the workers. This finding supports the earlier conclusion reached by Ofei-Kwapong (2013). Ofei-Kwapong (2013) revealed that the new pension scheme is not providing the right protection as it is expected. This means that the intended reason for introducing the Tier 2 pension scheme is yet to realise its full effectiveness from the perspective of the Ghanaian public sector workers in Central Region.

Overall, the study has revealed there is dearth of information on the tier 2 in the public sector. The information that exist to the stakeholders is scanty and hence negatively affect their perception of how management of the tier 2 would impact their future pension benefits. This finding is consistent with the assumption of the rational choice theory. One argument that emerges from making informed decision as far as the rational choice theory is concerned is based on thorough knowledge. The implication is that, if the public sector staff have all the information concerning the management of the Tier 2, it broadens their knowledge on it and hence lessens the agitation against it (Hindmoor, \& Taylor, 2015; Yeboah, 2015). However, the findings revealed that many people within the public sector have less knowledge on how the management of the tier 2 fund and the extent to which it could smoothen their future consumption.

The second research question of this paper seeks to assess the overall effectiveness of the management of the tier 2: What is the level of effectiveness in the management of Tier 2 pension scheme in public sector?

The respondent revealed that the Tier 2 is being controlled by the government and therefore they have limited knowledge on how it will affect their pensions. Some of the respondents further indicated that, they understand that the tier 2 is to be managed by a private fund management. However, majority of them do not know their fund manager. One of the participants stated that:

"For now, I am not aware which pension fund management is entrusted with our second tier. I have over heard 
our leaders making demand of it but am yet to know whether our leaders have been successful with demanding the fund management of the second tier form the government" (PT \# 4)

The implication is that though some of the public servant are aware that mandatory tier 2 is to be managed by private fund management, the disclosure of such fund management has become a struggle between leaders of some public sector workers and the government. Due to the lack of information on the management of the tier 2, some of the respondent indicated that they doubt whether indeed the government who is the employer is making payment into the fund. The responses from the study participants further revealed they do not know how much is being deposited into the tier 2 fund management monthly. This makes it difficult for them to tell whether or not the fund would be beneficial to them upon retirement. One stated as follows:

"........... I am unable to comment on the effectiveness.................for me to objectively assess the effectiveness of the tier 2 on my pension, then I have to know how much is being invested for me monthly or yearly. However, as I speak to you now, I do not have these details so how effective is the scheme" (PT \# 19).

Another participant reiterated that

"I believe the new pension scheme is the best, however, the divisions in it sometimes makes it difficult to actually know the role each of them plays. The second tier for instance, we should be able to know which private fund management is controlling the investment" (PT \# 13)

The responds from PT \# 13 correspond with that of PT \# 19. The basic explanation to these responses is that the tier fund manager is not known to many of the public sector workers and also do not know how much is invested and this makes it difficult to measure it effectiveness and how it will impact their pensions in the future.

The responds further indicated payment benefits under the tier 2 pension scheme could be very less due to the nature of fund that would be employed. The respondents raised concern about the fact that some investment plans are tied with macroeconomic development. Thus, the actual returns on investment could be far lesser than expected (PT\#5; PT\#11). These respondents therefore indicated that instead of the government controlling which private pension management to be used for the tier 2, the option should be left in the hand of the staffs. To make the management of the fund effective, the respondents indicated that the National Pension Regulatory Authority, should be proactive in its mandate of ensuring effective and efficient management of the new pension scheme under which the tier 2 falls.

The overall information gathered from the respondents present mixed results in relation to the effectiveness of the management of the tier 2 pension scheme. Some of the respondents indicated that the choice of the fund management being controlled by the government does not make the fund transparent and hence doubt its effectiveness. Other indicated that the actual amount contributed to the fund either monthly or yearly is not known and could not be readily verified since the private fund management is not known (PT\#3, 4, 7). From another perspective, some of the participants indicated that the fund could give some value in the future. However, these second group reiterated that, the type of investment plan could stifle the future benefits and hence reduce the expected returns (PT\#5, 9,11).

The findings do not adhere to the transparent principles advocated by the permanent income hypothesis. The theory argues that individual workers have the desire to save for the future in order for their household consumption not to depreciate upon retirement but rather put them on a level platform or provide permanent income (Afrane, et al 2016; Grebe, 2015). Thus, the introduction of the Tier 2 pension scheme which afford workers to be appoint their fund management for their retirement benefits should be as transparent as the Tier 1. Meanwhile the findings revealed that the government control of fund management reduces the transparency in the scheme and negatively affect its effectiveness.

The implications of the assumptions of the PIH helped to advocate that many stakeholders are of the view that management of pensions schemes which stems from the deduction of contributor's income should be left for individual workers or better yet their trade union. Ironically, the findings revealed that within the public sector, how the government is treating the Tier 2 is oblivious to the workers and hence cast doubt on its potential impact on their pensions. This observation is consistent with previous findings (Alidu et al, 2016). Additionally, the findings are consistent with that of Donkor (2016). Donkor revealed that the defined contribution as exhibited by the current pension plan may promise higher benefits relative to a defined benefit benchmark, however, it is subject to more risk hence pension ratios are less predictable.

\subsection{Conclusion and Recommendation}

The study examined the management of the Tier 2 pension scheme in the public sector and its impact on staff pension (Smoothen consumption and effectiveness). The focus was on the MMDAs in the Central Region of Ghana. Exploratory design was employed for the study supported by qualitative research approach. Interview was used as means of data collection after which data was recorded and edited. The study concluded that the effectiveness of the Tier 2 pension management is not satisfactory. This is because the government controls which private fund management is to be used. Moreover, contributors in the public sector do not know the amount of money that 
invested and the mode of payment (i.e monthly or yearly). The study further concluded that there is limited knowledge on the Tier 2 in the public sector. It is also concluded that many of the people in the public sector cannot ascertain the true benefit of the Tier 2 scheme on their future pension

Further implication of the study findings is that there is inadequate information on the true nature of the Tier 2 pension scheme. It is therefore recommended that the NPRA should make conscious effort to sensitize the general public with primary focus on the public sector sector about the Tier 2 pension scheme. Moreover, for workers to better plan for retirement they must possess adequate knowledge of their pension scheme. It is therefore recommended for government to organize workshops or seminars to educate their employees in the public sector on their pension schemes, identify the prospects and challenges associated with the scheme early enough to assist workers to make informed decisions about their retirement. It is also recommended that government leave the choice of Tier 2 private pension fund management in the hands of the public sector unions. This will make it easier for staff to track the progress of their funds and be abreast with future benefits.

\section{REFERENCE}

Afrane, S. K., Owusu-Manu, D., Donkor-Hyiaman, K. A., \& Bondinuba, F. K. (2016). Towards innovative housing financing in Ghana: an evidence-based from South Africa's pension housing financing system

Aikins, A. D. G., \& Apt, N. A. (2016). Aging in Ghana: Setting priorities for research, intervention and policy. Ghana Studies, 19(1), 35-45.

Alidu, S., Dankyi, E., \& Tsiboe-Darko, A. (2016). Aging policies in Ghana: A review of the livelihood empowerment against poverty and the National Health Insurance Scheme. Ghana Studies, 19(1), 154-172.

Ashong, G. I. B. (2019). Assessing the Effect of Second Tier Fund Management on Social Security and National Insurance Trust (SSNIT) Pension Scheme (Doctoral dissertation) University of Ghana. Spinger, UK

Badu, E., Kissi, E., Boateng, E. B., \& Antwi-Afari, M. F. (2018). Tertiary Educational Infrastructural Development in Ghana: Financing, Challenges and Strategies. Africa Education Review, 15(2), 65-81.Environment, 1-19.

Bogataj, D., \& Bogataj, M. (2017). Age management of human resources. SOR '17 proceedings, 235-241

Boudon, R. (2009). Rational choice theory. Journal of Social Research, 1(2) 179.

Darko, E. (2016). The Effectiveness of the Current Three-Tier Pension Scheme in Providing Adequate Social Security for Ghanaians: Evidence from the Eastern Region of Ghana (Doctoral dissertation) University of Ghana

Donkor, F. (2016). Defined Contribution and Defined Benefits: Inherent Risks and Risk Transfers in Ghanaian Pension Schemes (Doctoral dissertation) University of Ghana. Legon Press

Elster, J. (1989). Social norms and economic theory. Journal of economic perspectives, 3(4), 99117.

Friedman, J. (1994). Cultural identity and global process (Vol. 31). Sage. Bonn Germany

Grebe, E. (2015). The evolution of social protection policy in Ghana's 'Fourth Republic': Contributory social insurance reform and limited social assistance for the 'extreme poor'under NPP and NDC governments, 2000-2014. Doctoral dissertation) University of Ghana Press. Legon

Hindmoor, A., \& Taylor, B. (2015). Rational choice. Palgrave Macmillan Ltd. London, U.K

Mumba, B. (2016). Social Insurance Schemes and Income Security Among the Retired People in Zambia in Comparison to Mauritius, Tunisia, Ghana and Bolivia. Tunisia, Ghana and Bolivia (June 10, 2016).

Kamath, D. V., \& Patil, D. R. (2017). Cost Benefit Analysis of National Pension Scheme. International Journal of Management, 8(3).23-39

Kpessa, M. W. (2011). Retirement income security under Ghana's three-tier pension model: Assessment of risks and options for reform. Pensions: An International Journal, 16(2), 127-136.

Ofei-Kwapong, N. O. (2013). The role of Ghana's new three tier pension scheme and its effectiveness in providing social security for Ghanaians (Doctoral dissertation) Ashesi University College. Ghana

Ofori-Abebrese, G., Pickson, R. B., \& Abubakari, S. (2017). Assessing the impact of macroeconomic variables on pension benefits in Ghana: A case of Social Security and National Insurance Trust. South African Journal of Economic and Management Sciences, 20(1), 1-10.

Platanakis, E., \& Sutcliffe, C. (2017). Asset-liability modelling and pension schemes: the application of robust optimization to USS. The European Journal of Finance, 23(4), 324-352.

Poterba, J. M. (2019). Replication data for: Retirement Security in an Aging Population Sage Brussels. Belgium

Quartey, P., Kunawotor, M. E., \& Danquah, M. (2016). Sources of retirement income among formal sector workers in Ghana. African Journal of Economic and Management Studies 9.(3) 100-123

Slaug, B., Granbom, M., \& Iwarsson, S. (2020). An Aging Population and an Aging Housing stock-Housing Accessibility Problems in Typical Swedish Dwellings. Journal of Aging and population 3(4) 99-120

Yeboah, C. S. (2015). Social Security Pensions in the Informal Sector: The Perspectives of Farmers in the Shai Osu-Doku District (Doctoral dissertation) University of Ghana

Younger, S. D., Osei-Assibey, E., \& Oppong, F. (2017). Fiscal incidence in Ghana. Review of Development Economics, 21(4), 47-66. 